\title{
Review
}

\section{MicroRNAs and Calcium Signaling in Heart Disease}

\author{
Jae-Ho Park ${ }^{1}(\mathbb{D})$ and Changwon Kho ${ }^{2, *}$ (1) \\ 1 Division of Metabolism and Nutrition, Korea Food Research Institute, Iksan 55365, Korea; \\ jaehopark@kfri.re.kr \\ 2 Division of Applied Medicine, School of Korean Medicine, Pusan National University, Yangsan 50612, Korea \\ * Correspondence: khochangwon@pusan.ac.kr; Tel.: +82-51-510-8467
}

check for

updates

Citation: Park, J.-H.; Kho, C.

MicroRNAs and Calcium Signaling in Heart Disease. Int. J. Mol. Sci. 2021,

22, 10582. https://doi.org/10.3390/ ijms221910582

Academic Editor:

Hideyuki Yamawaki

Received: 31 August 2021

Accepted: 28 September 2021

Published: 30 September 2021

Publisher's Note: MDPI stays neutral with regard to jurisdictional claims in published maps and institutional affiliations.

Copyright: (c) 2021 by the authors. Licensee MDPI, Basel, Switzerland. This article is an open access article distributed under the terms and conditions of the Creative Commons Attribution (CC BY) license (https:/ / creativecommons.org/licenses/by/ $4.0 /)$.

\begin{abstract}
In hearts, calcium $\left(\mathrm{Ca}^{2+}\right)$ signaling is a crucial regulatory mechanism of muscle contraction and electrical signals that determine heart rhythm and control cell growth. $\mathrm{Ca}^{2+}$ signals must be tightly controlled for a healthy heart, and the impairment of $\mathrm{Ca}^{2+}$ handling proteins is a key hallmark of heart disease. The discovery of microRNA (miRNAs) as a new class of gene regulators has greatly expanded our understanding of the controlling module of cardiac $\mathrm{Ca}^{2+}$ cycling. Furthermore, many studies have explored the involvement of miRNAs in heart diseases. In this review, we aim to summarize cardiac $\mathrm{Ca}^{2+}$ signaling and $\mathrm{Ca}^{2+}$-related miRNAs in pathological conditions, including cardiac hypertrophy, heart failure, myocardial infarction, and atrial fibrillation. We also discuss the therapeutic potential of $\mathrm{Ca}^{2+}$-related miRNAs as a new target for the treatment of heart diseases.
\end{abstract}

Keywords: calcium signaling; microRNA; cardiac hypertrophy; heart failure; myocardial infarction; atrial fibrillation

\section{Introduction}

Heart disease (HD) is a major concern in global health. The number of patients with heart disease worldwide has nearly doubled in the last 10 years [1]. According to the latest update, HD remains the leading cause of death worldwide [1,2]. HD is a major economic burden. The global cost of medical care for heart failure (HF) has been estimated to increase from approximately USD 863 billion (2010) to USD 1044 billion (2030) [3,4].

The coronavirus disease 2019 (COVID-19) is spreading worldwide, with over 170 million infected and 3.7 million deaths across nearly 200 countries. People with HD or those who have had a stroke are associated with an increased risk of severe complications from COVID-19 [5]. There is growing evidence that COVID-19 is more deadly for patients with HD, including acute myocardial infarction (MI), arrhythmias, and HF [5,6]. According to experts, COVID-19 infection may directly affect heart health and mortality rates for many years owing to increased lifestyle-related risks during and after the pandemic [1]. In 2020 (during the COVID-19 pandemic), US HD deaths increased by $4.8 \%$, the largest increase in HD deaths since 2012 [7]. To date, except for invasive and expensive surgical procedures, there is no complete treatment to prevent or cure HD progression. Understanding the molecular mechanisms underlying the pathogenesis of HD is valuable for the development of effective therapeutic strategies and novel therapeutic targets for HD.

In the heart, calcium ions $\left(\mathrm{Ca}^{2+}\right)$ are critical for regulating muscle contraction, and abnormal $\mathrm{Ca}^{2+}$ homeostasis in cardiac cells is critical in the pathogenesis of common HD. In this review, we will describe the role of the main $\mathrm{Ca}^{2+}$ handling proteins in cardiac function and recent findings related to the mechanism of regulation of $\mathrm{Ca}^{2+}$ homeostasis via microRNAs (miRNAs) in diseased hearts and their potential for HD therapy.

\section{Roles of Calcium in Heart Contractility}

$\mathrm{Ca}^{2+}$ is an important signaling molecule in all cell types and regulates the fundamental functions of various organs. The heart uses $\mathrm{Ca}^{2+}$ to maintain the cardiac rhythm and muscle 
function. $\mathrm{Ca}^{2+}$-induced signals also cause cardiac cell damage or death due to hypoxia. The heart pumps blood throughout the body as a key organ in the circulatory system. The adult human heart is composed of many types of cells that combine to form complex structures. Cardiac muscle cells or cardiomyocytes occupy $\sim 75 \%$ of the structural volume [8] and are responsible for permanent blood flow by producing contractile force in intact hearts. Approximately three billion cardiomyocytes are activated by both electrical and mechanical stimuli to contract simultaneously.

As the typical ratio of the $\mathrm{Ca}^{2+}$ concentration to cytosolic concentration in the external cellular environment is close to 1:20,000, tight control of $\mathrm{Ca}^{2+}$ access to cells and efficient means of pumping $\mathrm{Ca}^{2+}$ are required. Changes in its concentration are responsible for many metabolic processes in the human body. For each beat, the intracellular free $\mathrm{Ca}^{2+}$ concentration in cardiomyocytes $\left(\left[\mathrm{Ca}^{2+}\right]_{\mathrm{i}}\right)$ increases above $1 \mu \mathrm{M}$, allowing interaction between the contractile elements during systole and diastole, and $\left[\mathrm{Ca}^{2+}\right]_{\mathrm{i}}$ decreases to approximately $100 \mathrm{nM}$, causing dissociation of the contractile elements [9]. It induces relaxation, allowing the heart to refill the blood. To elevate $\left[\mathrm{Ca}^{2+}\right]_{\mathrm{i}}$, extracellular $\mathrm{Ca}^{2+}$ enters the cytoplasm across the plasma membrane (sarcolemma), or intracellular $\mathrm{Ca}^{2+}$ is released from $\mathrm{Ca}^{2+}$ storage organelles, including the sarcoplasmic reticulum (SR). In cardiomyocytes, the sarcolemma $\mathrm{Na}^{+} / \mathrm{Ca}^{2+}$ exchanger (NCX) is the primary mechanism by which $\mathrm{Ca}^{2+}$ is released from cells. Activation of the sarco/endoplasmic reticulum $\mathrm{Ca}^{2+}$-adenosine triphosphatase 2 (SERCA2) pump promotes the reuptake of cytosolic $\mathrm{Ca}^{2+}$ into the SR. Numerous other molecules are involved in $\mathrm{Ca}^{2+}$ homeostasis in cardiomyocytes [10]. Cellular extrinsic and intrinsic signals influence cardiac function by modulating the magnitude and timing of $\mathrm{Ca}^{2+}$ transients in various cardiac regulating pathways. A summary of $\mathrm{Ca}^{2+}$ cycling observed in cardiomyocytes is presented in Figure 1.

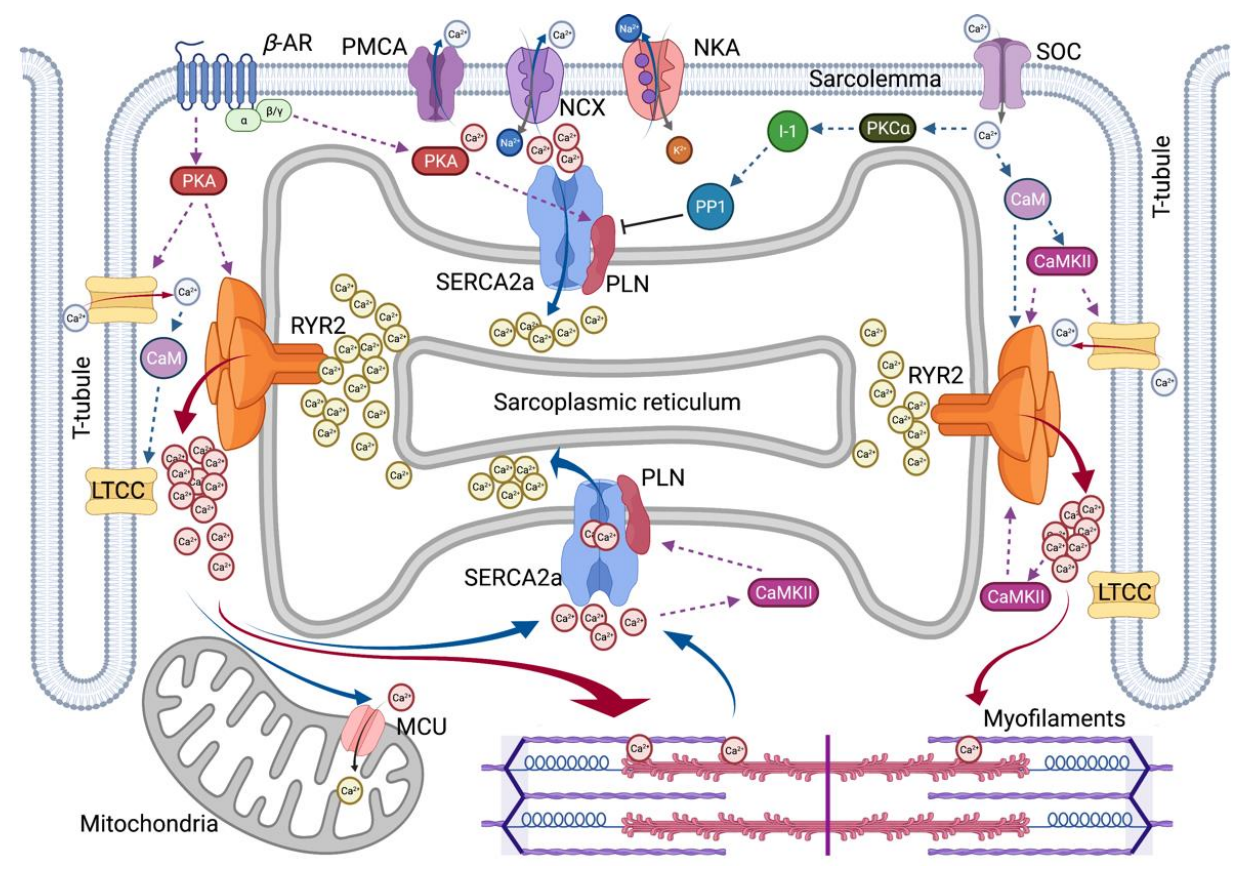

Figure 1. Overview of Intracellular $\mathrm{Ca}^{2+}$ Cycling in Cardiomyocytes. Schematic overview summarizes excitation-contraction coupling in cardiomyocytes. $\beta \mathrm{AR}, \beta$-adrenergic receptor; CaM,

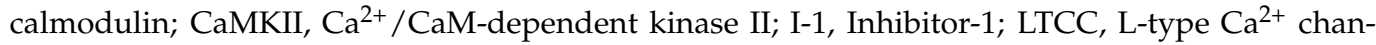
nel; MCU, Mitochondrial $\mathrm{Ca}^{2+}$ uniporter; $\mathrm{NCX}, \mathrm{Na}^{+} / \mathrm{Ca}^{2+}$ exchanger; $\mathrm{NKA}, \mathrm{Na}^{+} / \mathrm{K}^{+}$-ATPase; PKA, Protein kinase A; PKC $\alpha$, Protein kinase C $\alpha$-isoform; PLN, Phospholamban; PMCA, Plasma membrane $\mathrm{Ca}^{2+}$-ATPase; PP1, Protein phosphatase-1; RYR2, Ryanodine receptor type-2; SERCA2a, Sarco/endoplasmic reticulum $\mathrm{Ca}^{2+}$-adenosine triphosphatase 2; and SOC, store-operated channel. Red solid arrow represents $\mathrm{Ca}^{2+}$-induced $\mathrm{Ca}^{2+}$ release. Blue solid arrow represents $\mathrm{Ca}^{2+}$ extrusion in diastolic relaxation. Dotted lines represent a positive or negative effect on the following molecules. 


\subsection{Excitation-Contraction Coupling}

The contraction movement of hearts is carried out by excitation-contraction coupling (ECC), which occurs in cardiomyocytes through $\mathrm{Ca}^{2+}$ regulation [10]. $\mathrm{Ca}^{2+}$ regulation in cardiomyocytes is maintained by the action of specific proteins, such as $\mathrm{Ca}^{2+}$ channels, pumps, transporters, and exchangers. The SR serves as an important repository and sinks with the regulation of $\left[\mathrm{Ca}^{2+}\right]_{i}$ during ECC, and in cardiomyocytes, most $\mathrm{Ca}^{2+}$ is stored in the $\mathrm{SR}$ within the milli-molar range. $\mathrm{Ca}^{2+}$-buffering proteins (e.g., calsequestrin, CSQ) within the SR lumen are important $\mathrm{Ca}^{2+}$ sensors and contribute to deciphering $\mathrm{Ca}^{2+}$ transients and signals during ECC.

Cardiac ECC is the process whereby an electrical stimulation (i.e., excitation) of the surface membrane with an action potential (AP) triggers a cardiomyocyte to depolarize and contract. $\mathrm{Ca}^{2+}$ plays two pivotal roles in the ECC. $\mathrm{Ca}^{2+}$ drives myofilament activation and regulates sarcolemma ionic currents that are responsible for normal electrical rhythms. A series of ECC events in cardiomyocytes are as follows: (1) initiation and propagation of an AP along with the plasma membrane, (2) rapid spread of the potential along with the transverse tubule system (T-tubule system), (3) dihydropyridine receptors (DHPR, L-type $\mathrm{Ca}^{2+}$ channel CaV1.1, LTCC)-mediated detection of changes in membrane potential, (4) ryanodine receptors (RyRs) stimulation due to allosteric interaction of the LTCC with the SR RyRs, (5) release of $\mathrm{Ca}^{2+}$ through stimulated RyRs in SR and transient increase in $\left[\mathrm{Ca}^{2+}\right]_{\mathrm{i}}$, (6) transient activation of the cytosolic $\mathrm{Ca}^{2+}$ buffering system and the contractile apparatus, followed by (7) disappearance of $\mathrm{Ca}^{2+}$ from the cytosol mediated by its movement to the mitochondria via the mitochondrial $\mathrm{Ca}^{2+}$ uniporter (MCU), its expulsion by the NCX and plasma membrane $\mathrm{Ca}^{2+}$-ATPase (PMCA) at the sarcolemma, and its final reuptake by the SR through the SERCA2. Both the duration and intensity of cardiac AP affect the regulation of $\mathrm{Ca}^{2+}$ fluxes and contractility in cardiomyocytes.

In addition, ECC is regulated by multiple signaling pathways. The $\beta$-adrenergic pathway is regulated by $\beta$-agonists, such as adrenaline, which activate the $\beta$-adrenergic receptor ( $\beta \mathrm{AR}$ ) and initiates the production of cyclic adenosine monophosphate (cAMP) by adenylate cyclase, which activates protein kinase A (PKA). Another pathway is the $\mathrm{Ca}^{2+}$-mediated calmodulin (CaM)-dependent kinase (CaMK) signaling, which is activated by increased cytosolic $\mathrm{Ca}^{2+}$ content, thereby inducing regulation of ECC. More recent studies have reported a process called excitation-transcription coupling (ETC), which reveals a similar role of $\mathrm{Ca}^{2+}$ in controlling gene transcription in cardiomyocytes to that of $\mathrm{Ca}^{2+}$-dependent signaling of excitation-contraction coupling [11].

\subsection{Two Major Players in SR Calcium Flux in Heart Disease}

ECC defects that cause contractile dysfunction and cardiac arrhythmia are typical features of HF. In failing cardiomyocytes, a major defect in $\mathrm{Ca}^{2+}$ cycling occurs at the SR. $\mathrm{Ab}$ normal expression and function of key $\mathrm{Ca}^{2+}$ handling proteins, including SERCA2a, RyR2, phospholamban (PLN), CaM, CSQ2, triadin, and junctin, result in excessive $\left[\mathrm{Ca}^{2+}\right]_{\mathrm{i}}$, decreased SR $\mathrm{Ca}^{2+}$ uptake, increased SR Ca ${ }^{2+}$ leak, and decreased SR $\mathrm{Ca}^{2+}$ content. SERCA2a and RyR2 are primarily responsible for the sequestration and release of $\mathrm{SR} \mathrm{Ca}^{2+}$. Both SERCA2a and RyR2 are regulated by post-translational modifications (PTMs) and interacting partner proteins. Therefore, strategies to restore impaired SR Ca ${ }^{2+}$ homeostasis caused by an abnormality in these two $\mathrm{Ca}^{2+}$ handling proteins have been extensively studied for the treatment of HF. The major $\mathrm{SR} \mathrm{Ca}^{2+}$-handling proteins reported to be associated with HD are summarized in Table 1. 
Table 1. SR Calcium Handling Protein Associated with Human Heart Diseases.

\begin{tabular}{ccc}
\hline Protein & Disease Phenotype & References \\
\hline RyR2 & CPVT, ARVD/C2, AF & Priori et al., 2001 [12]; Marks et al., 2002 [13]; Yano et al., \\
& & 2005 [14] \\
SERCA2a & HF & Hasenfuss et al., 1994 [15]; Meyer et al., 2006 [16]; Flesch \\
PLN & ARVD, DCM & et al., 1996 [17] \\
CSQ2 & CPVT & Zwaag et al., 2012 [18]; Jordan et al., 2021 [19] \\
CaM & CPVT, LQTS & Lahat et al., 2001 [20]; Postma et al., 2002 [21] \\
Triadin & CPVT & Chazin and Johnson. 2020 [22] \\
Junctin & DCM & Roux-Buisson et al., 2012 [23]; Rooryck et al., 2015 [24] \\
HRC & Arrhythmias, DCM, AF & Arvanitis et al., 2008 [26]; Amioka et al., 2019 [27] \\
\hline
\end{tabular}

$\mathrm{AF}$, atrial fibrillation; ARVD, arrhythmogenic right ventricular dysplasia; ARVD/C2 arrhythogenic right ventricular cardiomyopathy type 2; CPVT, catecholaminergic polymorphic ventricular tachycardia; DCM, dilated cardiomyopathy; HF, heart failure; and LQTS, long QT syndrome.

\subsubsection{SERCA2a Calcium Pump}

One of the most striking cellular changes in failing human hearts is an increase in end-diastolic $\left[\mathrm{Ca}^{2+}\right]_{i}$ and prolongation of diastolic $\mathrm{Ca}^{2+}$ decay. SERCA2a is the dominant SERCA isoform in hearts and determines the clearance of more than $70 \%$ of cytosolic $\mathrm{Ca}^{2+}$ in humans and $90 \%$ of cytosolic $\mathrm{Ca}^{2+}$ in rodents [10]. Dysregulation of SERCA2a is a hallmark of HF. Several studies have shown that SERCA activity is diminished in failing human and animal hearts. Indeed, normalization of SERCA2a expression has been shown to significantly improve contractility and $\mathrm{Ca}^{2+}$ homeostasis in failing human cardiomyocytes [28] and increase hemodynamics with antiarrhythmic effects in rodent and large animal models of HF $[29,30]$. Therefore, restoration of SERCA2a function is an attractive therapeutic approach. SERCA2a gene therapy, which increases gene expression, and small molecule drugs, which stimulate enzyme activity, are being developed as new treatments for chronic HF. Several clinical studies have been conducted to correct SERCA2a enzyme abnormalities, such as CUPID (Calcium Upregulation by Percutaneous Administration of Gene Therapy in Cardiac Disease) 1, CUPID 2, AGENT-HF (AAV1-CMV-Serca2a Gene Therapy Trial in Heart Failure), and SERCA-LVAD trial [31-34]. These studies showed that SERCA2a gene delivery is safe and has potential benefits in advanced HF.

The typical underlying mechanism for reduced SERCA2a activity is inhibition by interacting with partner proteins. PLN is a reversible regulator of SERCA2a. PLN binds directly to SERCA2a and inhibits its affinity for $\mathrm{Ca}^{2+}$. The inhibition of SERCA2a by PLN is regulated by the phosphorylation of PLN rather than by changes in PLN expression. It has been observed that PLN phosphorylation is reduced in the heart tissues of most patients with HF $[35,36]$. $\beta$ AR stimulation leads to PLN phosphorylation at the serine-16 site by PKA and threonine-17 site by CaMKII or protein kinase B (AKT). Phosphorylated PLN loses its binding to SERCA2a, which in turn increases SERCA2a pump activity. In addition, several PLN-binding proteins, such as hematopoietic lineage cell-specific protein-1 associated protein X-1 (HAX-1), intra-luminal histidine-rich $\mathrm{Ca}^{2+}$ binding protein (HRC), S100A1, and protein phosphatase 1 (PP1), contribute to PLN-dependent SERCA2a regulation [37]. In 2016, Nelson et al. discovered a muscle-specific long noncoding RNA called the dwarf open reading frame (DWORF) as a novel activator of SERCA. The DWORF peptide has been proposed to indirectly activate SERCA2a by displacing PLN [38]. However, more diverse studies are needed to determine the exact physiological role of DWORF in the heart. Some studies have reported a reduction in PLN mRNA levels in patients with dilated or ischemic cardiomyopathy [17]. Notably, pathogenic variants in PLN, known to be associated with hereditary dilated cardiomyopathy (DCM) with HF, have been reported to cause problems with binding affinity for SERCA2a. Genetic correction of PLN mutations via genome editing techniques combined with gene transfer produced positive results, including normalized $\mathrm{Ca}^{2+}$ handling in a patient-derived cell model of DCM, suggesting a novel strategy for DCM treatment [39]. In particular, with strong support from the Leducq 
Foundation, an international network of excellence program in cardiovascular research, PLN-induced cardiomyopathy studies have become intensive [40].

SERCA2a function is also regulated by PTMs, including nitrosylation, glutathionylation, glycation, SUMOylation, and acetylation. In particular, SUMO1 deficiency and decreased SUMOylation levels of SERCA2a have been observed in failing hearts [41]. Restoration of SUMO1 via gene transfer has explored the therapeutic potential of targeting SUMOylation as a method to increase SERCA2a activity and improve cardiac contractility in both mouse and porcine models of HF [41-43]. Furthermore, this PTM framework provides a new perspective on SERCA2a modulation, resulting in the identification of novel SUMO-SERCA2a activators [44]. Recent work has uncovered additional roles of deacetylation/acetylation in modulating SERCA2a function during HF [45]. Overall, these PTMs are considered a fine-tuning mechanism of SERCA2a, which may enhance the capacity of active targeting SERCA2a to treat HF.

\subsubsection{RyR2 Calcium Release Channel}

RyR2 is a gate-keeping mechanism that serves as a $\mathrm{Ca}^{2+}$-induced $\mathrm{Ca}^{2+}$ release channel on the SR during the systole of cardiomyocytes. The amount of SR Ca ${ }^{2+}$ released by RyR2 is correlated with the strength of the systolic contraction. RyR2 is the largest ion channel in nature (four monomers of $565 \mathrm{kDa}$ each). RyR2 combines with numerous accessory proteins to form a large macromolecular complex, including FKBP (FK506-binding protein 12.6), CaM, CSQ2, junctin, triadin, HRC, S100A1, and Sorcin [46]. They control the $\mathrm{Ca}^{2+}$ sensitivity of RyR2 through dynamic interactions, which in turn alters the probability of RyR2 opening or closing. For example, loss or dysfunction of CSQ2, the main SR $\mathrm{Ca}^{2+}$ binding protein, exposes RyR2 to excess free $\mathrm{SR} \mathrm{Ca}^{2+}$. As another example, defective CaM binding to RyR2 destabilizes the channel. Indeed, several CaM mutations are associated with severe forms of long QT syndrome (LQTS) and catecholaminergic polymorphic ventricular tachycardia (CPVT) [22].

In addition, the gating ability of RyR2 is regulated by various PTMs, including phosphorylation, oxidation, and nitrosylation [47]. Many studies have shown that SR $\mathrm{Ca}^{2+}$ leaks are caused by increased sensitivity of RyRs to $\mathrm{Ca}^{2+}$ due to RyR phosphorylation by kinases (i.e., PKA or CaMKII) or phosphatases (i.e., phosphatase 1 or $2 \mathrm{~A}$ ). In particular, phosphorylation of RyR2 to specific serine residues, such as Ser-2808, Ser-2814, and Ser2030, appears to induce functional changes in RyR2, and an association with HD has been reported [48]. For example, PKA-mediated RyR2 induces the dissociation of FKBP, a RyR2 stabilizer, which increases the probability of opening. In this context, prolonged PKA phosphorylation may lead to premature contractions and arrhythmias. However, contradictory results have been reported for RyR2-mediated $\mathrm{Ca}^{2+}$ spark via phosphorylation in intact cardiomyocytes [48,49].

Under pathogenic conditions such as HF, RyR2-mediated $\mathrm{SR} \mathrm{Ca}^{2+}$ release continues during diastole, reducing SR Ca ${ }^{2+}$ content. RyR2 leakage can be due to altered expression levels of RyR2-associated proteins or dysregulation of PTMs, such as enhanced PKA- and CaMKII-dependent phosphorylation and reduced phosphatase activity. The exacerbating effects of SR $\mathrm{Ca}^{2+}$ leakage on cardiac function include: (1) decreased systolic SR $\mathrm{Ca}^{2+}$ levels leading to systolic dysfunction, (2) elevation of diastolic $\mathrm{Ca}^{2+}$ leading to diastolic dysfunction, (3) energy outflow to re-pump $\mathrm{Ca}^{2+}$, and (4) induced arrhythmias. Although there is no change in the protein expression of RyR2 in patients with $\mathrm{HF}$, abnormal $\mathrm{Ca}^{2+}$ sparks are observed in failing cardiomyocytes [50]. The exact mechanisms and regimes of SR operation that generate abnormal $\mathrm{Ca}^{2+}$ leaks remain elusive. Several abnormal functions of RyR2 have been identified in patients with CPVT, arrhythmic right ventricular cardiomyopathy (ARVC), or atrial filtration (AF) as the causes of disease-related mutations and interacting partners [12-14,51].

Regarding therapeutics, RyR2 gene replacement approaches are limited owing to the vector size. Alternatively, siRNA delivery to silence mutant mRNA of RyR2 in an allele-specific manner or genome-editing approach has proven effective in normalizing 
cardiac electrophysiology in a mouse model of CPVT [52]. Several types of drugs have been developed that target mutated or dysfunctional RyR2 channels, including benzothiazepine derivatives (K201 and S107), tetracaine derivatives (EL9 and EL20), and unnatural verticilide enantiomers [53]. The potential of K201 for the treatment of AF has been evaluated clinically; however, the results have not been reported. Several FDA-approved drugs modulate RyR2, including flecainide and propafenone, which are anti-arrhythmic agents that act as $\mathrm{Na}^{+}$channel blockers with additional activity in the open state of RyR2. Dantrolene, a pan-RyR inhibitor, has been investigated for its anti-arrhythmic efficacy in patients with CPVT (NCT04134845) [53].

\subsection{Calcium Signaling through Protein Kinases}

As described above, $\mathrm{Ca}^{2+}$ cycling is achieved through harmony with vital $\mathrm{Ca}^{2+}$ handling proteins strictly regulated by changes in PTMs, such as phosphorylation. The most relevant modulator for these proteins is PKA, which can directly phosphorylate and regulate major proteins in cardiomyocytes, including LTCC, RyR2, and PLN. A further mechanism of control is provided by CaMKII, targeting the same $\mathrm{Ca}^{2+}$ handling proteins.

\section{4. $\beta$-Adrenergic Receptor-Mediated PAK Regulation}

PKA is a cAMP-dependent protein kinase that has multiple roles in the regulation of cardiac function, including contraction, metabolism, ion flux, and gene transcription. A principle underlying the mechanism of cardiac $\beta$-adrenergic receptor ( $\beta A R)$ signal transduction is as follows: in response to stress, the binding of agonist $\beta$ ARs selectively interacts with the stimulatory $G$ protein to directly stimulate adenylyl cyclase, converting ATP to cAMP, which activates PKA. $\beta$ AR-mediated PKA activation phosphorylates several ECC proteins such as LTCC, RyR, cardiac troponin I (cTnI), cardiac myosin binding protein $\mathrm{C}$ (cMyBPC), and PLN. An additional critical target in $\mathrm{Ca}^{2+}$ cycling is inhibitor-1 (I-1), which is also controlled by PKA. I-1 becomes active upon PKA phosphorylation and inhibits type 1 serine/threonine protein phosphatase (PP1), resulting in amplification of $\beta A R$ responses in hearts.

Chronic HF is associated with increased sympathetic nervous system activity [54]. In the early stages of reduced cardiac function, an increase in sympathetic activity preserves cardiac output. As heart function deteriorates, activation of neurohumoral signaling pathways increases to compensate for disease progression. However, prolonged neurohormonal activation causes significant damage to cardiomyocytes. Under long-term stimulation, $\beta A R$ signaling is regulated by the coordinated action of at least three enzymes, both at the receptor level and downstream of the cascade: $G$ protein-coupled receptor kinases, which phosphorylate and desensitize the receptor; cyclic nucleotide phosphodiesterases, which degrade CAMP; and phosphatases, which dephosphorylate phosphoproteins. Chronic stimulation of $\beta A R$ results in multiple changes in the ARAR signaling cascade, including downregulation of $\beta A R$, upregulation of $\beta A R$ kinase, and increased inhibitory G-protein $\alpha$-subunit function. In this context, it is a foregone conclusion that abnormalities in the $\beta A R-P K A$ pathway are important determinants of cardiac dysfunction and HF. Reduced PKA activity and decreased phosphorylation of downstream targets such as PLN, cTnI, and $\mathrm{cMyBP}$, have been observed in patients with AF, hypertrophic cardiomyopathy, and HF [55-57]. However, increased protein levels and activity of PKA have also been reported in failing hearts [58]. PKA-mediated hyperphosphorylation of RyR2 is found in dysfunctional human and canine hearts, associated with RyR2 channel instability creating leaky channels. Although there are contradictory reports on the expression level and activity of PKA in diseased hearts, aberrant PKA activation or inactivation contributes to the pathogenesis of myocardial ischemia, hypertrophy, and HF.

\subsection{Calcium-Calmodulin Mediated CaMKII Regulation}

CaMKII is another critical regulatory kinase responsible for the phosphorylation of key ECC proteins and the transcriptional activation of pathological hypertrophy $[59,60]$. 
CaMKII is inactive in normal status, but is activated by increased $\left[\mathrm{Ca}^{2+}\right]_{i}$ and reactive oxygen species (ROS). Initially, the elevation of $\left[\mathrm{Ca}^{2+}\right]_{i}$ triggers $\mathrm{Ca}^{2+}$ binding to $\mathrm{CaM}$, activating CaMKII. Activation of CaMKII by $\mathrm{Ca}^{2+}-\mathrm{CaM}$ depends on the local $\mathrm{Ca}^{2+}$ level and the frequency of $\mathrm{Ca}^{2+}$ release. When $\left[\mathrm{Ca}^{2+}\right]_{i}$ increases briefly, CaMKII returns to its inactive form after $\mathrm{Ca}^{2+}-\mathrm{CaM}$ dissociation. However, the continuous presence of $\mathrm{Ca}^{2+}-\mathrm{CaM}$ allows for autophosphorylation of CaMKII, which causes "CaM trapping" to maintain CaMKII activity even at low $\left[\mathrm{Ca}^{2+}\right]_{i}$ conditions. For example, CaMKII can be activated through PTMs induced by ROS independent of $\mathrm{Ca}^{2+}-\mathrm{CaM}$ but also activated in response to $\beta A R / P K A$ stimulation [61].

CaMKII is considered a major pathogenic signaling molecule in HD [62-64]. For example, upregulation of CaMKII activity and expression appears to be a common hallmark of cardiomyopathy of various etiologies in patients and animal models, suggesting that CaMKII is a signaling molecule in cardiomyopathy. Given the vital role of CaMKII in ion channel regulation, CaMKII seems to behave as a pro-arrhythmogenic protein in the heart. The expression and activity of CaMKII increase in AF, resulting in the promotion of arrhythmogenesis. Besides arrhythmias, oxidized, constitutively active CaMKII has been strongly linked with ischemia/reperfusion injury (I/R), diabetes cardiomyopathy, and HF.

\section{MicroRNAs as a New Modulator of Calcium Signaling Pathway}

MicroRNAs (miRNAs) are small, noncoding RNAs consisting of approximately 18-24 nucleotides that regulate gene expression and function at the post-transcriptional and translational levels. These molecules are expected to alter expression by $20-30 \%$ of all mammalian protein-coding genes [65]. A single miRNA can regulate multiple genes as targets, and many miRNAs can target a single gene. In addition, miRNAs can indirectly affect the expression of other miRNAs. Recent miRNA studies often (1) define expression patterns by microarray profiling or random sequencing; (2) identify downstream targets through bioinformatic analysis with in vitro validation; and (3) determine miRNA-related phenotypes.

In hearts, miRNAs broadly demonstrate their roles in physiological and pathological events $[66,67]$. Specific miRNAs can influence several aspects of the onset and progression of HD, such as pathological hypertrophy, fibrosis, inflammation, apoptosis, and oxidative and hypoxic damage. Cardiac $\mathrm{Ca}^{2+}$-handling proteins and signaling pathways are also regulated by miRNAs [68]. In addition, circulating miRNAs have also been shown to be promising biomarkers for HD [69]. Current studies suggest that the expression profile of many cardiovascular-related miRNAs may be altered by diet $[70,71]$. In this section, we focus on miRNAs related to $\mathrm{Ca}^{2+}$ homeostasis. The important miRNAs implicated in the pathophysiology of $\mathrm{HD}$ regulating $\mathrm{Ca}^{2+}$ homeostasis, along with their targets, are summarized in Table 2 and Figure 2.

Table 2. Calcium Regulating miRNAs in Heart Diseases.

\begin{tabular}{|c|c|c|c|c|}
\hline microRNA ID & $\begin{array}{c}\text { Pathways Related Target } \\
\text { Genes }\end{array}$ & $\begin{array}{c}\mathrm{Ca}^{2+} \text { Homeostasis } \\
\text { Related Target Genes }\end{array}$ & Changes in HD & References \\
\hline $\operatorname{miR}-1$ & $\begin{array}{c}\text { Cell differentiation, heart } \\
\text { development }\end{array}$ & NCX1, RyR2, MCU & $\begin{array}{c}\text { Down in HF, HT, ICM or } \\
\text { Up in DCM }\end{array}$ & \multirow{12}{*}{$\begin{array}{c}\text { Barwari et al., } 2016 \text { [67]; } \\
\text { Harada et al., } 2014 \text { [68]; } \\
\text { Watson et al., } 2015 \text { [72]; } \\
\text { Quan et al., } 2018 \text { [73]; Oh } \\
\text { et al., } 2018 \text { [74] }\end{array}$} \\
\hline miR-21 & Inflammation & LTCC & Up in HT, DCM, CM & \\
\hline miR-22 & Apoptosis & SERCA2a & Up in $\mathrm{HT}, \mathrm{HF}$ & \\
\hline miR-25 & Heart development & SERCA2a, MCU & Up in HF & \\
\hline miR-132 & Cell proliferation & NCX1 & Up in HT, DCM & \\
\hline miR-133 & Cardiac hypertrophy & RyR2 & $\begin{array}{l}\text { Down in HF, HT, AF, } \\
\text { DCM, ICM or Up in CM }\end{array}$ & \\
\hline miR-145 & Heart development & CaMKIIऽ & Up in DCM, AS & \\
\hline miR-146a & Inflammation & SUMO1 & Up in HF \& CHD & \\
\hline $\operatorname{miR}-214$ & Cardiac hypertrophy & NCX1, CaMKII $\delta$ & Up in MI, DCM, ICM, AS & \\
\hline $\operatorname{miR}-328$ & Fibrosis & SERCA2a, LTCC & Down in HF or Up in HT & \\
\hline $\operatorname{miR}-494$ & Apoptosis & СаMKII & Down in IHD, MI & \\
\hline miR-574 & Apoptosis & SERCA2a & Up in MI & \\
\hline
\end{tabular}

$\mathrm{AF}$, atrial fibrillation; $\mathrm{AS}$, aorta stenosis; $\mathrm{CHD}$, coronary heart disease; $\mathrm{DCM}$, dilated cardiomyopathy; HF; heart failure; HT, hypertrophy; ICM, ischemic cardiomyopathy; and MI, myocardial infarction. 


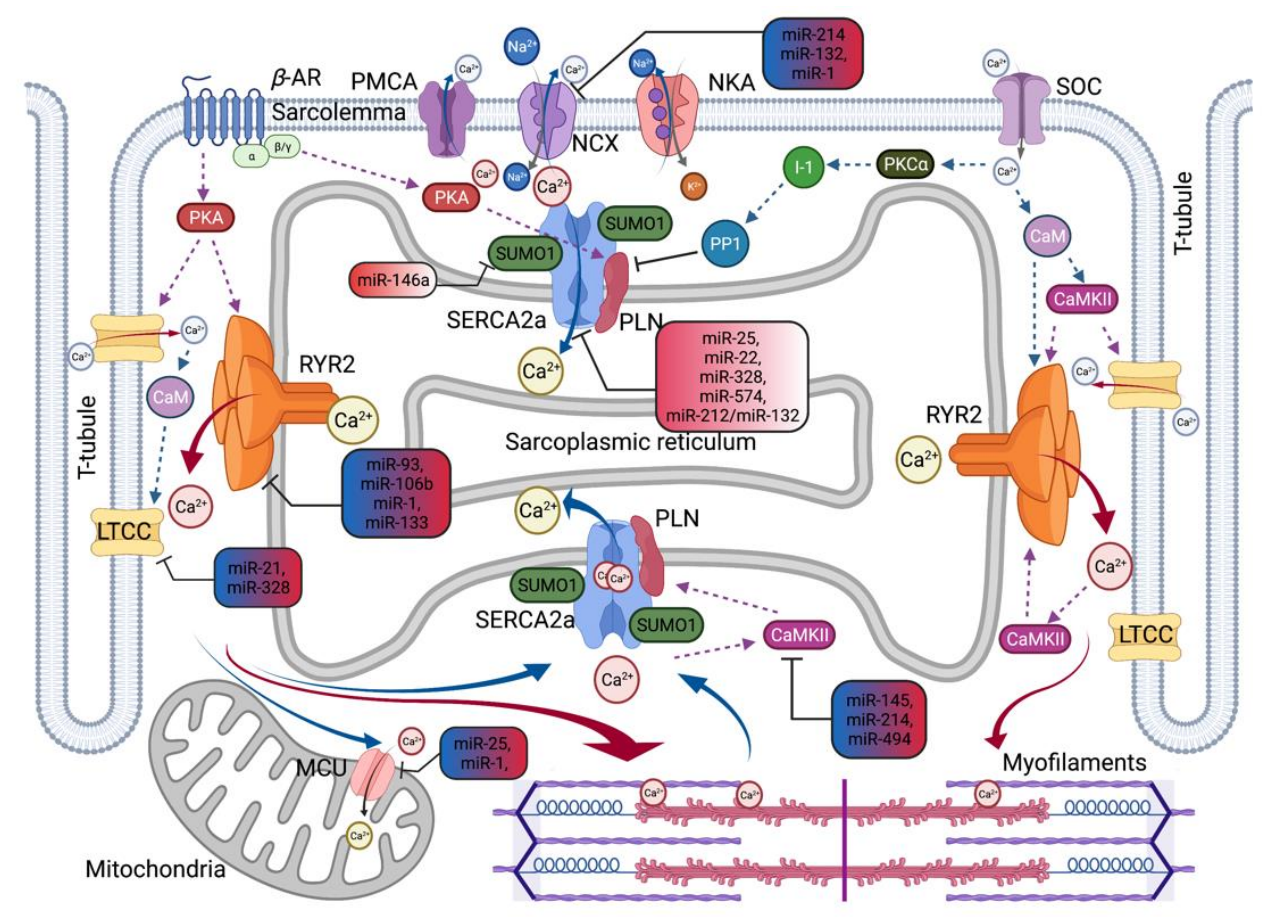

Figure 2. MicroRNA-Regulated Changes in Calcium Cycling in Heart Diseases. Schematic overview summarizes miR-mediated regulation of key $\mathrm{Ca}^{2+}$ handling proteins in heart diseases. CaMKII, $\mathrm{Ca}^{2+} / \mathrm{CaM}$-dependent kinase II; LTCC, L-type $\mathrm{Ca}^{2+}$ channel; $\mathrm{MCU}$, Mitochondrial $\mathrm{Ca}^{2+}$ uniporter; $\mathrm{NCX}, \mathrm{Na}^{+} / \mathrm{Ca}^{2+}$ exchanger; RYR2, Ryanodine receptor type-2; SERCA2a, Sarcoplasmic reticulum $\mathrm{Ca}^{2+}$-adenosine triphosphatase 2; and SUMO1, Small ubiquitin-like modifier type 1. Red solid arrow represents $\mathrm{Ca}^{2+}$-induced $\mathrm{Ca}^{2+}$ release. Blue solid arrow represents $\mathrm{Ca}^{2+}$ extrusion in diastolic relaxation. Dotted lines represent a positive or negative effect on the following molecules. Upregulated miRNAs represent in a red gradient-filled rounded rectangle. The varying expression changed miRNAs in heart disease represent in both blue and red gradient-filled rounded rectangles.

\subsection{Calcium Regulating MicroRNAs Related to Hypertrophy and Heart Failure}

Cardiac hypertrophy (HT) is an abnormal enlargement or thickening of the heart muscle that occurs as an adaptive response to hemodynamic overload, which increases contractility and reduces ventricular wall stress. This adaptive hypertrophy transits to HF through pathological remodeling [75]. Pathological cardiac hypertrophy is commonly observed in patients with hypertension or heart valve stenosis. The major signaling pathway for pathological hypertrophy is $\mathrm{Ca}^{2+}$-dependent hypertrophic signaling such as angiotensin II (ET-1)/Gaq/calcineurin/NFAT [76]. The critical role of the SR Ca ${ }^{2+}$ transport system in HT/HF has been consistently demonstrated both in transgenic animals and by gene therapy to improve impaired $\mathrm{Ca}^{2+}$ handling. The relationship between pathological hypertrophy-related miRNA processes has also been extensively studied.

Early studies on Dicer knockout, a critical enzyme of miRNA biogenesis, have implicated a critical role for miRNAs in cardiac development and physiology. Da Costa Martins et al. reported that cardiac-specific deletion of Dicer leads to pathogenic cardiac remodeling and functional defects [77]. In 2006, Van Rooij et al. first reported more than a dozen miRNAs regulated in cardiomyocytes during HT or HF in mice and humans [78]. In this study, the expression of miR-24, miR-125b, miR-195, miR-199a, and miR-214 increased in both the hearts of patients with end-stage HF and in HF mice, indicating a general response pattern of adverse cardiac remodeling. To date, the regulatory function of specific miRNAs associated with cardiac HT/HF has been studied, and the list of disease-related miRNAs continues to grow. For example, miR-1, miR-9, miR-19b, miR-21, miR-23a, miR-26, miR-29, miR-98, miR-132, miR-133, miR-155, miR-195, miR-199a/b, miR-208, and miR-499 are known to contribute to pathological hypertrophy. 
miR-1 is one of the best-characterized miRNAs to date. In general, miR-1 is present in clusters with miR-133, and both miR-1 and miR-133 are among the most abundantly expressed miRNAs in hearts. miR-1 expression is linked to several transcription factors, including serum response factor (SRF), myoblast determination protein 1, and myocyte enhancer factor-2, which may be promoted by $\beta$ AR activation-mediated PKA signaling [79]. To assess cardiomyocyte $\mathrm{Ca}^{2+}$ homeostasis, gap junction protein alpha 1 or connexin 43 (Gja1), potassium inwardly rectifying channel subfamily J member 2 or Kir2.1 (Kcnj2), sorcin (Sri), protein phosphatase 2 regulatory subunit B'alpha or PP2A-B56 $\alpha$ (Ppp2r5a), NCX1 (Ncx1), and calmodulin (calm) were predicted and characterized as target genes of miR-1. A reduction in miR-1 expression in failing hearts has been reported in many studies. Ikeda et al. reported that miR-1 is downregulated in tissues of patients with dilated cardiomyopathy and aortic stenosis, and tends to be downregulated in ischemic cardiomyopathy hearts [80]. Cardiomyocyte-specific miR-1 overexpression was found to have anti-hypertrophic properties. Karakikes et al. showed that AAV9-mediated miR-1 gene delivery restores intracellular $\mathrm{Ca}^{2+}$ transient rates and kinetics and improves contractile dysfunction in rats with pressure-overload-induced HT [81]. They concluded that the beneficial effects of miR-1 are due to fine-tuned calcium metabolism through normalization of the Ncx1/Serca $2 a$ ratio. In contrast, miR-1 downregulation during HF suppresses miR-26 expression by increasing calcineurin-NFAT activity. The miR-26 family has been demonstrated to be an essential regulator of cardiac remodeling. The expression of miR-26 family has been observed to be downregulated in experimental animals and human patients with HF [82].

miR-22 is abundantly expressed in hearts; however, an altered expression of miR22 was observed in diseased hearts. miR-22 plays an essential role in regulating the transition from HT to dilated cardiomyopathy in response to pathological stresses, such as $\beta$-adrenergic stimulation or cardiac pressure overload. Gurha et al. reported that genetic deletion of miR-22 accelerates pathogenic cardiac remodeling and HF development [83]. miR-22 knockout cardiomyocytes exhibited SR Ca ${ }^{2+}$ handling abnormalities, particularly SERCA2a transporting activity, Serca2a levels, and decreased PLN phosphorylation. Several miR-22 target genes have been reported, including sirtuin 1 and purine-rich elementbinding protein B (PURB) $[83,84]$. PURB is a repressor of SRF, a transcriptional regulator of the Serca2a gene, and hypertrophic genes.

Wahlquist et al. found that upregulation of miR-25 in failing hearts inhibited the expression of SERCA2a [85]. In mice, miR-25 overexpression reduced cardiac contractile properties, but conversely, miR-25 inhibition by injection of anti-miR-25 oligonucleotides (antagomiR) improved cardiac function and animal survival in the setting of HF. Further studies showed that miR-25 could be efficiently inhibited over a long time by administering adeno-associated virus (AAV) vectors encoding an anti-miR-25 tough decoy (TuD) in vivo [86]. The protective effects of miR-25 inhibition were observed during the progression of HF. These studies suggest the potential for HF treatment by targeting miR-25, due to its ability to modulate the clinically validated target SERCA2a. In addition, Let-7, miR-24-3p, miR-133a-3p, miR-140, miR-141-3p, miR-142-3p, miR-148-3p, and miR-153-3p have been reported as potential regulators of SERCA2a in HD.

Interestingly, another miRNA involved in the regulation of the SERCA2a pump function is miR-146a. miR-146 has been implicated in the immune response. In immune cells, miR-146 expression is induced upon inflammatory stimuli, and it is also an NF- $\mathrm{kB}$ transcriptional target. Several studies have indicated the role of miR-146a in the pathogenesis of HD. Oh et al. reported the mechanical association of miR-146a with hypertension-induced cardiac HT and HF [74]. miR-146a transcript levels increased in both animals and HF patients and were inversely correlated with Sumo1 expression, a positive regulator of the SERCA2a pump. In in vitro experiments, the decay of the $\mathrm{Ca}^{2+}$ transient was prolonged in miR-146a overexpressed cardiomyocytes due to decreased sumo1 expression. AAV-mediated cardiac miR-146a overexpression caused contractile dysfunction and reduced SUMOylated SERCA2a and SERCA2a protein itself, as well as SUMO levels. However, restoration of 
SUMO1 and SERCA2a molecules through TuD-mediated miR-146a inhibition improved cardiac function and hemodynamics and suppressed cardiac remodeling in mice subjected to transverse aorta constriction. Another study found that pharmacological inhibition of miR-146a via antagomir injection attenuated cardiac dysfunction and inhibited cardiac remodeling in rats with MI-induced HF [87]. Previous studies have shown that miR-146a can be used as a potential biomarker to evaluate the efficacy of anti-HF agents [88].

SERCA2a is also a target of miR-328 and has been studied in in vitro and in vivo models of HT. Li et al. reported that miR-328 increased upon HT stimuli and demonstrated that the overexpression of miR-328 promoted cardiac HT accompanied with decreased SERCA2a expression and increased $\left[\mathrm{Ca}^{2+}\right]_{i}[89]$. In addition, miR-328 alters the LTCC current by directly targeting the LTCC subunits, CCNB2, thereby increasing the susceptibility of the heart to arrhythmia. The expression of miR-328 increased 3.5 times in atrial tissue in AF patients [90].

Expression levels of the $\mathbf{m i R}-\mathbf{2 1 2} / \mathbf{m i R}-\mathbf{1 3 2}$ cluster were upregulated in cardiomyocytes under hypertrophic conditions. The miR-212/miR-132 family is a calcineurin/NFAT signaling cascade regulator that directly downregulates the anti-hypertrophic Forkhead box protein O3 (Foxo3) transcription factor. Ucar et al. reported that miR-212/132 knockout mice protect cardiac function from pressure-overload-induced HF, whereas cardiac miR212/132 overexpressing mice displayed pathological HT and HF phenotypes [91]. Recent studies have shown that the miR-212/132 family also regulates SERCA2a by targeting the 3'-UTR of the Serca2a gene [92]. Preclinical studies have been conducted to develop anti-miR-132 therapeutics. Foinquinos et al. reported the therapeutic efficacy of a synthetic antisense oligonucleotide inhibitor against miR-132 (antimiR-132) in a pig model of postMI [93]. CDR132L, the first antimiR-132 agent, recently completed clinical evaluation in a Phase 1b study (NCT04045405) that demonstrated safety and acceptable pharmacokinetics and is suggested to improve cardiac function in patients with HF [93].

Additionally, it was reported that dysfunction of miR-30, miR-148/152, and miR-625 is likely to be associated with $\mathrm{Ca}^{2+}$-dependent signaling during cardiac HT and HF through the inhibition of CaMKII.

\subsection{Calcium Regulating MicroRNAs Related to Ischemic Heart Disease}

Ischemic heart disease or myocardial infarction (MI) is the most common underlying cause of HF. In pathological hypertrophy, adverse cardiac remodeling after myocardial ischemia eventually leads to cardiac dysfunction and decreased performance. Among the complex signaling networks that characterize myocardial remodeling, the distinct processes are cardiomyocyte loss, cardiac hypertrophy, alteration of extracellular matrix homeostasis, fibrosis, autophagy defects, metabolic abnormalities, and mitochondrial dysfunction.

Although reperfusion strategies to reduce ischemic injury are widely used in clinics for MI, reperfusion following ischemia (I/R) injury is an important complication of this therapy. Cardiomyocyte death, arrhythmias, and contractile dysfunction are the main signs of myocardial I/R injury. Defects in the myocardial $\mathrm{Ca}^{2+}$ transport system with cytosolic $\mathrm{Ca}^{2+}$ overload are significant contributors to myocardial I/R injury [94]. Reductions in SERCA2a activity and SR $\mathrm{Ca}^{2+}$ uptake have been reported in most myocardial I/R studies. Consistently, the rate of SR $\mathrm{Ca}^{2+}$ reuptake significantly decreased in the human myocardium after reverse I/R. Several studies have reported that I/R-mediated cytosolic $\mathrm{Ca}^{2+}$ overload can be reduced by pharmacological inhibition of reverse-mode NCX activity. In addition, altered expression or activity of LTCCs and CaMKII, and oxidative modifications of $\mathrm{Ca}^{2+}$ handling proteins after I/R injury have been reported in experimental animals.

Many studies have suggested that miRNAs are associated with the progression of myocardial I/R injury and MI $[95,96]$. For example, miRNA-1, miRNA-15, miRNA-92a, miRNA-320, and miRNA-574 can have detrimental effects on I/R injured hearts. miRNA21, miRNA-24, and miRNA-29 appear to play dual roles in the pathogenesis of cardiac I/R injury. In contrast, miRNA-126, miRNA-133, miRNA-144, miRNA-145, miRNA-199, 
miRNA-210, miRNA-214, miRNA-494, miRNA-451, and miRNA-499 were found to protect the heart from I/R injury.

miR-214 is transcribed together with miR-199a-2 and is upregulated in response to various cardiac stresses, including pressure overload, MI, and excessive calcineurin, a calcium/calmodulin-sensitive phosphatase. Aurora et al. reported that miR-214 null mice exacerbated myocardial I/R injury due to loss of cardiac contractility, increased apoptosis, and excessive fibrosis [97]. Through gene expression profiling by microarrays, altered $\mathrm{Ca}^{2+}$ handling was confirmed in miR-214 knockout mouse hearts. miR-214 directly inhibited Ncx1, increasing NCX protein expression, and reverse mode activity miR-214 knockout mice. Furthermore, CaMKII, a key regulator of $\mathrm{Ca}^{2+}$ signaling, also contains a miR-214 binding site, and mRNA levels of CaMKII increased in miR-214 deficient hearts upon I/R compared to wildtype-controls.

miRNA-145 is enriched in hearts and is dysregulated in animal models after I/R injury. miR-145 is downregulated in MI rats, whereas upregulation of miR-145 expression promotes the repair of infarcted myocardium. In cardiomyocytes, miR-145 inhibits ROSinduced $\mathrm{Ca}^{2+}$ overload and $\mathrm{Ca}^{2+}$-related signals by directly targeting CaMKII [98].

miR-1 is also known to be involved in the I/R injury process [95]. While miR-1 is upregulated in remote areas of infarcted regions relative to healthy adult hearts, miR1 was downregulated in rat cardiac tissue post-I/R. By targeting several anti-apoptotic genes, miR-1 can affect either cardiac cell death or survival depending on the pathogenic conditions. The arrhythmia promoted by miR-1 is described below.

MicroRNA dysregulation due to I/R injury involves different reactions depending on the damage process. Acute inhibition or overexpression of miRNAs after MI might be beneficial in limiting tissue damage and preventing long-term adverse remodeling and HF.

\subsection{Calcium Regulating MicroRNAs Related to Atrial Fibrillation}

AF is a persistent cardiac arrhythmia, especially in the elderly, which can cause or exacerbate HF. Delayed afterdepolarizations (DADs) are the most important mechanisms underlying focal atrial activity [99]. AF atria show SR $\mathrm{Ca}^{2+}$ handling abnormalities, triggering spontaneous diastolic SR $\mathrm{Ca}^{2+}$ release. However, the $\mathrm{SR} \mathrm{Ca}^{2+}$ load was not increased significantly, suggesting that SR $\mathrm{Ca}^{2+}$ leaks occur due to altered RyR2 function. Excess diastolic $\mathrm{Ca}^{2+}$ is removed by NCX, creating a net depolarizing current called the transient inward current that produces DADs. Several studies have demonstrated that the level of RyR2 protein is elevated in the atria of patients with paroxysmal AF. In addition, increased NCX expression and function are commonly observed in AF. Altered $\mathrm{Ca}^{2+}$ signaling may also contribute to structural and electrical remodeling. For example, $\mathrm{Ca}^{2+}$ overload can activate the calcineurin-NFAT pathway, leading to HT and fibrosis.

The link between miR-1 and the onset of cardiac arrhythmia has been observed in animal models and humans. miR-1 expression is significantly upregulated in ventricular arrhythmias. The possible mechanisms of hyperactivated miR-1-mediated arrhythmia include enhanced $\mathrm{Ca}^{2+}$ release, dissociation of phosphatase activity from the RyR2 complex, and altered expression of $\mathrm{K}^{+}$channels that impairs the kinetics or membrane trafficking systems. Several studies have shown that miR-1 and miR-133 may indirectly increase calcium release by targeting B56 $\alpha$, a regulatory subunit of PP2A. Yang et al. found that miR-1 promotes ischemic cardiac arrhythmias by targeting the KCNJ2 gene, which encodes the Kir2.1 inward rectifier $\mathrm{K}^{+}$channel protein subunit, and the GJA1 gene, encoding connexin-43 gap junction channel protein subunit [100]. In addition, upregulation of miR-1 expression by aldosterone blocker treatment reduced the incidence of ventricular arrhythmias, in part, by targeting hyperpolarization-activated cyclic nucleotide-gated channels in MI rats [101]. In contrast, the expression of miR-1 was downregulated in patients with age-related AF and patients with advanced-stage AF undergoing cardiac surgery [102]. This increased miR-1 expression correlates with increased Kir2.1 transcript levels and inward rectifier $\mathrm{K}^{+}$current density. These results suggest different effects of miR- 
1 under other arrhythmia conditions; therefore, the exact mechanism of miR-1 mediated arrhythmia generation requires further study.

The miR-106b 25 cluster consists of the highly conserved miR-106b, miR-93, and miR25 and is downregulated in patients with paroxysmal AF, which is associated with elevated RyR2 expression. miR-106b and miR-93 could negatively regulate RyR2-3'UTR [103]. Moreover, loss of the miR-106b-25 family induced pro-arrhythmic SR Ca ${ }^{2+}$ release, resulting in increased AF sensitivity in mice.

The miR-208 (miR-208a/b) family is a cardiomyocyte-specific miRNA encoded within introns of the cardiac myosin heavy chain genes (i.e., MYH6 and MYH7). Of the two isoforms, increased miR-208b was consistently observed in tissues of damaged hearts, especially MI and dilated cardiomyopathy. Canon et al. observed upregulated miR-208b expression in AF cardiomyocytes [104]. Aberrant miR-208b levels, but not miR-208a, were inversely correlated with the mRNA levels of SERCA2a predicted as a direct target gene. Overexpression of miR-208b in HL-1 atrial myocytes showed reduced SERCA2 protein levels, suggesting the involvement of miR-208b in $\mathrm{Ca}^{2+}$ handling impairment during atrial remodeling.

In addition, upregulated miR-21, miR208b, and miR-328 contributed to adverse electrical remodeling in AF by targeting LTCC. In particular, miR-21 has been extensively studied for its role in atrial fibrosis during AF. Several studies have reported that circulating miR-208b and miR-328 are related to AF prevalence [105], suggesting a new biomarker for AF.

The modified miRNAs of hearts due to AF contribute to cardiac electrical and structural remodeling. A recent meta-analysis conducted by Shen et al. reported that 283 miRNAs changed compared to AF and non-AF controls [106]. Of the 51 consistent miRNAs (consistency of expression patterns), 22 miRNAs, including miR-155, miR-223, miR-483, and miR-1202, were upregulated in AF and 29, including miR-125b, miR-143, miR-145, and miR-208, were downregulated in AF.

\section{4. miRNAs as Potential Therapeutics for Heart Disease}

As our knowledge of the biosynthesis and functionality of miRNAs in hearts has increased over the past two decades, attempts have been made to identify HD-related miRNAs and understand mechanisms of action and downstream effectors for potential clinical applications. Inconsistent findings in the expression profiling of several miRNAs and miRNA-target relationships may be due to differences in HD models (types and stages of disease), sample sources, subjects of study, and technical issues. However, these discrepancies also indicate that miRNAs mediate gene regulation in a tissue-cell-specific manner for a particular disease state.

Various strategies are being used to modify miRNA levels through restoration/ replacement or suppression as a potential treatment method [107]. A specific miRNA gain-of-function can be achieved by synthesizing miRNAs called miRNA mimics. miRNA mimics are double-stranded RNA oligonucleotides that include one strand identical to endogenous mature miRNA, which generally increases the efficiency of miRNA expression. In addition, plasmid- and virus-based overexpression of miRNA precursors (i.e., primary miRNAs) allows exogenous miRNA expression in specific regions and cell types. In contrast, miRNA activity can be inhibited using specific synthetic miRNA antagonists with sequences complementary to the target miRNA, such as miRNA masks, anti-miR, antimiRNA antisense oligonucleotides (AMOs), locked-nucleic acids (LNA), or antagomiRs. A possible strategy to sufficiently target certain tissues after systemic administration is coupling the miRNA antagonists to a specific conjugate substance (e.g., GalNAc and GN3) or enveloping the miRNA antagonists in a vector (e.g., a lipid nanoparticle). Vector-based miRNA inhibitors, such as miRNA sponges, erasers, miRNA-mower, and TuD, offer alternative approaches to promote long-term expression and inhibitory efficacy. These techniques demonstrated effective inhibition of the target mRNA in vivo. 
Gene therapy has often been suggested as a technique to limit local approaches rather than systemic administration, including limited vector size, inefficient delivery to target tissues, and nuclear localization requirements for protein synthesis. In this context, miRregulated treatment based on gene therapy may be a better choice. miR regulators are much smaller, so there are no limitations on the size of the genes being delivered [108]. As $\mathrm{miR}$ regulators are necessary to enter only the cytosol of the target cell, whole-systemic delivery, which is also used in the siRNA approach, would be appropriate. However, there are several potential limitations in developing miRNA-based therapeutics regarding safety and efficacy, including optimizing miRNA chemical modifications and finding a suitable delivery system for a specific miRNA. Although it can be considered an advantage and a disadvantage, this is an innovative idea in terms of treating HD, a complex disease with multiple connecting signal paths. miRNAs may induce sequence-specific and nonspecific off-target effects, such as siRNAs [108], which can bind to entirely complementary nucleotide sequences and similar sequences. Meanwhile, several studies have reported that chemical modifications to siRNAs that mediate gene silencing may address these issues as they significantly reduce unintended regulation. Furthermore, miRNAs are considered less toxic than siRNAs as they are endogenous biomolecules. However, off-target studies using miRNAs are not well developed compared to siRNAs. In addition, the specificity of viral-mediated delivery issues that are not limited to miRNA therapy continues to be a challenge. Current approaches use cardiac muscle-specific promoters (e.g., cardiac troponin T or $\alpha$-cardiac myosin heavy chain) and viral serotypes (e.g., AAV1 and AAV9) that have been demonstrated to be introduced into cardiac cells [109].

To date, only a few miRNA-based drugs are still in the early phases of clinical trials, but there are clinical research efforts to investigate novel miRNA drug candidates for HD along with the miR-132 study (described above) [110]. For example, miRagen is developing MRG 110, an LNA-based miR-92a inhibitor, and Remlarsen (MRG201), a synthetic miRNA-29b mimic for the treatment of HF. Two other molecules, miRagen, MGN-9103 (a cardiacspecific miR-280a inhibitor) and MGN-1374 (a miR15/195 inhibitor), are in the preclinical stage for the treatment of chronic HF. Miravirsen was the first miRNA drug to participate in human trials. Studies have shown that systemic delivery of antagomiRs targeting hepatic miR-122 is beneficial in humans without long-term safety concerns, suggesting that miRNA therapeutics remain promising. Future studies should demonstrate the safety and efficacy of optimized delivery systems focusing on the clinical application of HD-related miRNA treatments.

\section{Conclusions}

In this review, we explored critical molecules involved in $\mathrm{Ca}^{2+}$ homeostasis in cardiac cells and the mechanisms of $\mathrm{Ca}^{2+}$ regulation through miRNAs, whose functions are altered during HD. A potential benefit of miRNA-based therapies is their ability to simultaneously target many genes in a given pathway and ease of application. Given the critical role of $\mathrm{Ca}^{2+}$ metabolism in cardiac pathophysiology, $\mathrm{Ca}^{2+}$ regulating miRNAs have significant potential as therapeutic agents in HD.

Author Contributions: Conceptualization, C.K. and J.-H.P.; writing-original draft preparation, C.K. and J.-H.P.; writing-review and editing, C.K. and J.-H.P.; and funding acquisition, C.K. and J.-H.P. All authors have read and agreed to the published version of the manuscript.

Funding: This research was funded by Research Grant of Pusan National University, 2020 and the Research Program of the Korea Food Research Institute, grant number E0210601-01.

Institutional Review Board Statement: Not applicable.

Informed Consent Statement: Not applicable.

Data Availability Statement: Not applicable.

Acknowledgments: We would like to thank Ahyoung Lee for her help in writing manuscripts and organizing ideas. 
Conflicts of Interest: The authors declare no conflict of interest.

\section{References}

1. Virani, S.S.; Alonso, A.; Aparicio, H.J.; Benjamin, E.J.; Bittencourt, M.S.; Callaway, C.W.; Carson, A.P.; Chamberlain, A.M.; Cheng, S.; Delling, F.N.; et al. Heart Disease and Stroke Statistics-2021 Update: A Report From the American Heart Association. Circulation 2021, 143, e254-e743. [CrossRef] [PubMed]

2. Roth, G.A.; Mensah, G.A.; Johnson, C.O.; Addolorato, G.; Ammirati, E.; Baddour, L.M.; Barengo, N.C.; Beaton, A.Z.; Benjamin, E.J.; Benziger, C.P.; et al. Global Burden of Cardiovascular Diseases and Risk Factors, 1990-2019: Update From the GBD 2019 Study. J. Am. Coll. Cardiol. 2020, 76, 2982-3021. [CrossRef]

3. Mohammadzadeh, N.; Safdari, R.; Rahimi, A. Multi-agent system as a new approach to effective chronic heart failure management: Key considerations. Healthc. Inform. Res. 2013, 19, 162-166. [CrossRef]

4. Roger, V.L.; Go, A.S.; Lloyd-Jones, D.M.; Benjamin, E.J.; Berry, J.D.; Borden, W.B.; Bravata, D.M.; Dai, S.; Ford, E.S.; Fox, C.S.; et al. Heart disease and stroke statistics-2012 update: A report from the American Heart Association. Circulation 2012, 125, e2-e220.

5. Clerkin, K.J.; Fried, J.A.; Raikhelkar, J.; Sayer, G.; Griffin, J.M.; Masoumi, A.; Jain, S.S.; Burkhoff, D.; Kumaraiah, D.; Rabbani, L.; et al. COVID-19 and Cardiovascular Disease. Circulation 2020, 141, 1648-1655. [CrossRef]

6. Nishiga, M.; Wang, D.W.; Han, Y.; Lewis, D.B.; Wu, J.C. COVID-19 and cardiovascular disease: From basic mechanisms to clinical perspectives. Nat. Rev. Cardiol. 2020, 17, 543-558. [CrossRef] [PubMed]

7. Ahmad, F.B.; Anderson, R.N. The Leading Causes of Death in the US for 2020. JAMA 2021, 325, 1829-1830. [CrossRef]

8. Bergmann, O.; Zdunek, S.; Felker, A.; Salehpour, M.; Alkass, K.; Bernard, S.; Sjostrom, S.L.; Szewczykowska, M.; Jackowska, T.; Dos Remedios, C.; et al. Dynamics of Cell Generation and Turnover in the Human Heart. Cell 2015, 161, 1566-1575. [CrossRef]

9. Fearnley, C.J.; Roderick, H.L.; Bootman, M.D. Calcium Signaling in Cardiac Myocytes. Cold Spring Harb. Perspect. Biol. 2011, 3, a004242. [CrossRef]

10. Bers, D.M. Cardiac excitation-Contraction coupling. Nature 2002, 415, 198-205. [CrossRef] [PubMed]

11. Dewenter, M.; von der Lieth, A.; Katus, H.A.; Backs, J. Calcium Signaling and Transcriptional Regulation in Cardiomyocytes. Circ. Res. 2017, 121, 1000-1020. [CrossRef] [PubMed]

12. Priori, S.G.; Napolitano, C.; Tiso, N.; Memmi, M.; Vignati, G.; Bloise, R.; Sorrentino, V.; Danieli, G.A. Danieli Mutations in the cardiac ryanodine receptor gene (hRyR2) underlie catecholaminergic polymorphic ventricular tachycardia. Circulation 2001, 103, 196-200. [CrossRef] [PubMed]

13. Tiso, N.; Stephan, D.A.; Nava, A.; Bagattin, A.; Devaney, J.M.; Stanchi, F.; Larderet, G.; Brahmbhatt, B.; Brown, K.; Bauce, B.; et al. Identification of mutations in the cardiac ryanodine receptor gene in families affected with arrhythmogenic right ventricular cardiomyopathy type 2 (ARVD2). Hum. Mol. Genet. 2001, 10, 189-194. [CrossRef] [PubMed]

14. Dridi, H.; Kushnir, A.; Zalk, R.; Yuan, Q.; Melville, Z.; Marks, A.R. Intracellular calcium leak in heart failure and atrial fibrillation: A unifying mechanism and therapeutic target. Nat. Rev. Cardiol. 2020, 17, 732-747. [CrossRef]

15. Hasenfuss, G.; Reinecke, H.; Studer, R.; Meyer, M.; Pieske, B.; Holtz, J.; Holubarsch, C.; Posival, H.; Just, H.; Drexler, H. Relation between myocardial function and expression of sarcoplasmic reticulum $\mathrm{Ca}\left({ }^{2+}\right)$-ATPase in failing and nonfailing human myocardium. Circ. Res. 1994, 75, 434-442. [CrossRef]

16. Meyer, M.; Schillinger, W.; Pieske, B.; Holubarsch, C.; Heilmann, C.; Posival, H.; Kuwajima, G.; Mikoshiba, K.; Just, H.; Hasenfuss, G. Alterations of sarcoplasmic reticulum proteins in failing human dilated cardiomyopathy. Circulation 1995, 92, 778-784. [CrossRef]

17. Flesch, M.; Schwinger, R.H.; Schnabel, P.; Schiffer, F.; van Gelder, I.; Bavendiek, U.; Südkamp, M.; Kuhn-Regnier, F.; Böhm, M. Sarcoplasmic reticulum $\mathrm{Ca}^{2+}$ ATPase and phospholamban mRNA and protein levels in end-stage heart failure due to ischemic or dilated cardiomyopathy. J. Mol. Med. 1996, 74, 321-332. [CrossRef] [PubMed]

18. Van der Zwaag, P.A.; van Rijsingen, I.A.; Asimaki, A.; Jongbloed, J.D.; van Veldhuisen, D.J.; Wiesfeld, A.C.; Cox, M.G.; van Lochem, L.T.; de Boer, R.A.; Hofstra, R.M.; et al. Phospholamban R14del mutation in patients diagnosed with dilated cardiomyopathy or arrhythmogenic right ventricular cardiomyopathy: Evidence supporting the concept of arrhythmogenic cardiomyopathy. Eur. J. Heart Fail. 2012, 14, 199-207. [CrossRef]

19. Hershberger, R.E.; Jordan, E. Dilated Cardiomyopathy Overview. GeneReviews [Internet]. 2007. Available online: https: / / pubmed.ncbi.nlm.nih.gov/20301486/ (accessed on 27 September 2021).

20. Lahat, H.; Pras, E.; Olender, T.; Avidan, N.; Ben-Asher, E.; Man, O.; Levy-Nissenbaum, E.; Khoury, A.; Lorber, A.; Goldman, B.; et al. A missense mutation in a highly conserved region of CASQ2 is associated with autosomal recessive catecholamine-induced polymorphic ventricular tachycardia in Bedouin families from Israel. Am. J. Hum. Genet. 2001, 69, 1378-1384. [CrossRef] [PubMed]

21. Postma, A.V.; Denjoy, I.; Hoorntje, T.M.; Lupoglazoff, J.M.; da Costa, A.; Sebillon, P.; Mannens, M.M.; Wilde, A.A.; Guicheney, P. Absence of calsequestrin 2 causes severe forms of catecholaminergic polymorphic ventricular tachycardia. Circ. Res. 2002, 91, e21-e26. [CrossRef]

22. Chazin, W.J.; Johnson, C.N. Calmodulin Mutations Associated with Heart Arrhythmia: A Status Report. Int. J. Mol. Sci. 2020, 21, 1418. [CrossRef] 
23. Roux-Buisson, N.; Cacheux, M.; Fourest-Lieuvin, A.; Fauconnier, J.; Brocard, J.; Denjoy, I.; Durand, P.; Guicheney, P.; Kyndt, F.; Leenhardt, A.; et al. Absence of triadin, a protein of the calcium release complex, is responsible for cardiac arrhythmia with sudden death in human. Hum. Mol. Genet. 2012, 21, 2759-2767. [CrossRef] [PubMed]

24. Rooryck, C.; Kyndt, F.; Bozon, D.; Roux-Buisson, N.; Sacher, F.; Probst, V.; Thambo, J.B. New Family With Catecholaminergic Polymorphic Ventricular Tachycardia Linked to the Triadin Gene. J. Cardiovasc. Electrophysiol. 2015, 26, 1146-1150. [CrossRef]

25. Gergs, U.; Berndt, T.; Buskase, J.; Jones, L.R.; Kirchhefer, U.; Müller, F.U.; Schlüter, K.D.; Schmitz, W.; Neumann, J. On the role of junctin in cardiac $\mathrm{Ca}^{2+}$ handling, contractility, and heart failure. Am. J. Physiol. Heart Circ. Physiol. 2007, 293, H728-H734. [CrossRef] [PubMed]

26. Arvanitis, D.A.; Sanoudou, D.; Kolokathis, F.; Vafiadaki, E.; Papalouka, V.; Kontrogianni-Konstantopoulos, A.; Theodorakis, G.N.; Paraskevaidis, I.A.; Adamopoulos, S.; Dorn, G.W., 2nd; et al. The Ser96Ala variant in histidine-rich calcium-binding protein is associated with life-threatening ventricular arrhythmias in idiopathic dilated cardiomyopathy. Eur. Heart J. 2008, 29, $2514-2525$. [CrossRef]

27. Amioka, M.; Nakano, Y.; Ochi, H.; Onohara, Y.; Sairaku, A.; Tokuyama, T.; Motoda, C.; Matsumura, H.; Tomomori, S.; Hironobe, N.; et al. Ser96Ala genetic variant of the human histidine-rich calcium-binding protein is a genetic predictor of recurrence after catheter ablation in patients with paroxysmal atrial fibrillation. PLoS ONE 2019, 14, e0213208. [CrossRef] [PubMed]

28. Del Monte, F.; Harding, S.E.; Schmidt, U.; Matsui, T.; Kang, Z.B.; Dec, G.W.; Gwathmey, J.K.; Rosenzweig, A.; Hajjar, R.J. Restoration of contractile function in isolated cardiomyocytes from failing human hearts by gene transfer of SERCA2a. Circulation 1999, 100, 2308-2311. [CrossRef]

29. Lyon, A.R.; Bannister, M.L.; Collins, T.; Pearce, E.; Sepehripour, A.H.; Dubb, S.S.; Garcia, E.; O'Gara, P.; Liang, L.; Kohlbrenner, E.; et al. SERCA2a gene transfer decreases sarcoplasmic reticulum calcium leak and reduces ventricular arrhythmias in a model of chronic heart failure. Circ. Arrhythm. Electrophysiol. 2011, 4, 362-372. [CrossRef]

30. Kawase, Y.; Ly, H.Q.; Prunier, F.; Lebeche, D.; Shi, Y.; Jin, H.; Hadri, L.; Yoneyama, R.; Hoshino, K.; Takewa, Y.; et al. Reversal of cardiac dysfunction after long-term expression of SERCA2a by gene transfer in a pre-clinical model of heart failure. J. Am. Coll. Cardiol. 2008, 51, 1112-1119. [CrossRef]

31. Hajjar, R.J.; Zsebo, K.; Deckelbaum, L.; Thompson, C.; Rudy, J.; Yaroshinsky, A.; Ly, H.; Kawase, Y.; Wagner, K.; Borow, K.; et al. Design of a phase $1 / 2$ trial of intracoronary administration of AAV1/SERCA2a in patients with heart failure. J. Card. Fail. 2008, 14, 355-367. [CrossRef]

32. Jaski, B.E.; Jessup, M.L.; Mancini, D.M.; Cappola, T.P.; Pauly, D.F.; Greenberg, B.; Borow, K.; Dittrich, H.; Zsebo, K.M.; Hajjar, R.J. Calcium Up-Regulation by Percutaneous Administration of Gene Therapy In Cardiac Disease (CUPID) Trial Investigators. Calcium upregulation by percutaneous administration of gene therapy in cardiac disease (CUPID Trial), a first-in-human phase 1/2 clinical trial. J. Card. Fail. 2009, 15, 171-181.

33. Hulot, J.S.; Salem, J.E.; Redheuil, A.; Collet, J.P.; Varnous, S.; Jourdain, P.; Logeart, D.; Gandjbakhch, E.; Bernard, C.; Hatem, S.N.; et al. AGENT-HF Investigators. Effect of intracoronary administration of AAV1/SERCA2a on ventricular remodelling in patients with advanced systolic heart failure: Results from the AGENT-HF randomized phase 2 trial. Eur. J. Heart Fail. 2017, 19, 1534-1541. [CrossRef] [PubMed]

34. Lyon, A.R.; Babalis, D.; Morley-Smith, A.C.; Hedger, M.; Suarez Barrientos, A.; Foldes, G.; Couch, L.S.; Chowdhury, R.A.; Tzortzis, K.N.; Peters, N.S.; et al. Investigation of the safety and feasibility of AAV1/SERCA2a gene transfer in patients with chronic heart failure supported with a left ventricular assist device-The SERCA-LVAD TRIAL. Gene Ther. 2020, 27, 579-590. [CrossRef] [PubMed]

35. Schmidt, U.; Hajjar, R.J.; Kim, C.S.; Lebeche, D.; Doye, A.A.; Gwathmey, J.K. Human heart failure: cAMP stimulation of SR $\mathrm{Ca}\left({ }^{2+}\right)$-ATPase activity and phosphorylation level of phospholamban. Am. J. Physiol. 1999, 277, H474-H480. [CrossRef] [PubMed]

36. Schwinger, R.H.; Munch, G.; Bolck, B.; Karczewski, P.; Krause, E.G.; Erdmann, E. Reduced Ca $\left({ }^{2+}\right)$-sensitivity of SERCA 2a in failing human myocardium due to reduced serin-16 phospholamban phosphorylation. J. Mol. Cell. Cardiol. 1999, 31, 479-491. [CrossRef]

37. Haghighi, K.; Bidwell, P.; Kranias, E.G. Phospholamban interactome in cardiac contractility and survival: A new vision of an old friend. J. Mol. Cell. Cardiol. 2014, 77, 160-167. [CrossRef]

38. Nelson, B.R.; Makarewich, C.A.; Anderson, D.M.; Winders, B.R.; Troupes, C.D.; Wu, F.; Reese, A.L.; McAnally, J.R.; Chen, X.; Kavalali, E.T.; et al. A peptide encoded by a transcript annotated as long noncoding RNA enhances SERCA activity in muscle. Science 2016, 351, 271-275. [CrossRef]

39. Karakikes, I.; Stillitano, F.; Nonnenmacher, M.; Tzimas, C.; Sanoudou, D.; Termglinchan, V.; Kong, C.W.; Rushing, S.; Hansen, J.; Ceholski, D.; et al. Correction of human phospholamban R14del mutation associated with cardiomyopathy using targeted nucleases and combination therapy. Nat. Commun. 2015, 6, 6955. [CrossRef]

40. Doevendans, P.A.; Glijnis, P.C.; Kranias, E.G. Leducq Transatlantic Network of Excellence to Cure Phospholamban-Induced Cardiomyopathy (CURE-PLaN). Circ. Res. 2019, 125, 720-724. [CrossRef]

41. Kho, C.; Lee, A.; Jeong, D.; Oh, J.G.; Chaanine, A.H.; Kizana, E.; Park, W.J.; Hajjar, R.J. SUMO1-dependent modulation of SERCA2a in heart failure. Nature 2011, 477, 601-605. [CrossRef]

42. Lee, A.; Jeong, D.; Mitsuyama, S.; Oh, J.G.; Liang, L.; Ikeda, Y.; Sadoshima, J.; Hajjar, R.J.; Kho, C. The role of SUMO-1 in cardiac oxidative stress and hypertrophy. Antioxid. Redox Signal. 2014, 21, 1986-2001. [CrossRef] 
43. Tilemann, L.; Lee, A.; Ishikawa, K.; Aguero, J.; Rapti, K.; Santos-Gallego, C.; Kohlbrenner, E.; Fish, K.M.; Kho, C.; Hajjar, R.J. SUMO-1 gene transfer improves cardiac function in a large-animal model of heart failure. Sci. Transl. Med. 2013, 5, 211 ra159. [CrossRef] [PubMed]

44. Kho, C.; Lee, A.; Jeong, D.; Oh, J.G.; Gorski, P.A.; Fish, K.; Sanchez, R.; deVita, R.J.; Christensen, G.; Dahl, R.; et al. Small-molecule activation of SERCA2a SUMOylation for the treatment of heart failure. Nat. Commun. 2015, 6, 7229. [CrossRef] [PubMed]

45. Gorski, P.A.; Jang, S.P.; Jeong, D.; Lee, A.; Lee, P.; Oh, J.G.; Chepurko, V.; Yang, D.K.; Kwak, T.H.; Eom, S.H.; et al. Role of SIRT1 in Modulating Acetylation of the Sarco-Endoplasmic Reticulum Ca ${ }^{2+}$-ATPase in Heart Failure. Circ. Res. 2019, 124, e63-e80. [CrossRef] [PubMed]

46. Zalk, R.; Lehnart, S.E.; Marks, A.R. Modulation of the ryanodine receptor and intracellular calcium. Annu. Rev. Biochem. 2007, 76, 367-385. [CrossRef] [PubMed]

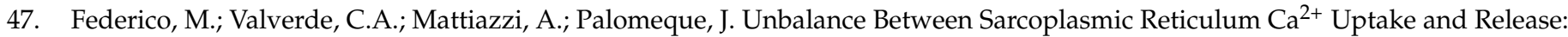
A First Step Toward Ca ${ }^{2+}$ Triggered Arrhythmias and Cardiac Damage. Front. Physiol. 2020, 10, 1630. [CrossRef] [PubMed]

48. Dobrev, D.; Wehrens, X.H. Role of RyR2 Phosphorylation in Heart Failure and Arrhythmias. Circ. Res. 2014, 114, 1311-1319. [CrossRef]

49. Li, Y.; Kranias, E.G.; Mignery, G.A.; Bers, D.M. Protein kinase A phosphorylation of the ryanodine receptor does not affect calcium sparks in mouse ventricular myocytes. Circ. Res. 2002, 90, 309-316. [CrossRef]

50. Marx, S.O.; Reiken, S.; Hisamatsu, Y.; Jayaraman, T.; Burkhoff, D.; Rosemblit, N.; Marks, A.R. PKA phosphorylation dissociates FKBP12.6 from the calcium release channel (ryanodine receptor): Defective regulation in failing hearts. Cell 2000, 101, 365-376. [CrossRef]

51. Belevych, A.E.; Radwanski, P.B.; Carnes, C.A.; Gyorke, S. 'Ryanopathy': Causes and manifestations of RyR2 dysfunction in heart failure. Cardiovasc. Res. 2013, 98, 240-247. [CrossRef]

52. Bongianino, R.; Denegri, M.; Mazzanti, A.; Lodola, F.; Vollero, A.; Boncompagni, S.; Fasciano, S.; Rizzo, G.; Mangione, D.; Barbaro, S.; et al. Allele-Specific Silencing of Mutant mRNA Rescues Ultrastructural and Arrhythmic Phenotype in Mice Carriers of the R4496C Mutation in the Ryanodine Receptor Gene (RYR2). Circ. Res. 2017, 121, 525-536. [CrossRef] [PubMed]

53. Patrick, C.; Tarah, A.W.; Xander, H.T.W. Targeting Pathological Leak of Ryanodine Receptors: Preclinical Progress and the Potential Impact on Treatments for Cardiac Arrhythmias and Heart Failure. Expert Opin. Ther. Targets 2020, 24, 25-36.

54. Packer, M. The neurohormonal hypothesis: A theory to explain the mechanism of disease progression in heart failure. J. Am. Coll. Cardiol. 1992, 20, 248-254. [CrossRef]

55. El-Armouche, A.; Boknik, P.; Eschenhagen, T.; Carrier, L.; Knaut, M.; Ravens, U.; Dobrev, D. Molecular determinants of altered $\mathrm{Ca}^{2+}$ handling in human chronic atrial fibrillation. Circulation 2006, 114, 670-680. [CrossRef] [PubMed]

56. Zakhary, D.R.; Moravec, C.S.; Stewart, R.W.; Bond, M. Protein kinase A (PKA)-dependent troponin-I phosphorylation and PKA regulatory subunits are decreased in human dilated cardiomyopathy. Circulation 1999, 99, 505-510. [CrossRef] [PubMed]

57. Jacques, A.M.; Copeland, O.; Messer, A.E.; Gallon, C.E.; King, K.; McKenna, W.J.; Tsang, V.T.; Marston, S.B. Myosin binding protein C phosphorylation in normal, hypertrophic and failing human heart muscle. J. Mol. Cell. Cardiol. 2008, 45, 209-216. [CrossRef] [PubMed]

58. Wang, J.; Liu, X.; Arneja, A.S.; Dhalla, N.S. Alterations in protein kinase A and protein kinase C levels in heart failure due to genetic cardiomyopathy. Can. J. Cardiol. 1999, 15, 683-690.

59. Maier, L.S.; Zhang, T.; Chen, L.; DeSantiago, J.; Brown, J.H.; Bers, D.M. Transgenic CaMKIIdeltaC overexpression uniquely alters cardiac myocyte $\mathrm{Ca}^{2+}$ handling: Reduced SR Ca ${ }^{2+}$ load and activated SR Ca ${ }^{2+}$ release. Circ. Res. 2003, 92, 904-911. [CrossRef]

60. Zhang, M.; Hagenmueller, M.; Riffel, J.H.; Kreusser, M.M.; Bernhold, E.; Fan, J.; Katus, H.A.; Backs, J.; Hardt, S.E. Calcium/calmodulin-dependent protein kinase II couples Wnt signaling with histone deacetylase 4 and mediates dishevelledinduced cardiomyopathy. Hypertension 2015, 65, 335-344. [CrossRef]

61. Erickson, J.R. Mechanisms of CaMKII activation in the heart. Front. Pharmacol. 2014, 5, 59. [CrossRef]

62. Swaminathan, P.D.; Purohit, A.; Hund, T.J.; Anderson, M.E. CaMKII: Linking heart failure and arrhythmias. Circ. Res. 2012, 110, 1661-1677. [CrossRef]

63. Bell, J.R.; Vila-Petroff, M.; Delbridge, L.M. CaMKII-dependent responses to ischemia and reperfusion challenges in the heart. Front. Pharmacol. 2014, 5, 96. [CrossRef]

64. Hegyi, B.; Bers, D.M.; Bossuyt, J. CaMKII signaling in heart diseases: Emerging role in diabetic cardiomyopathy. J. Mol. Cell. Cardiol. 2019, 127, 246-259. [CrossRef]

65. Lewis, B.P.; Burge, C.B.; Bartel, D.P. Conserved seed pairing, often flanked by adenosines, indicates that thousands of human genes are microRNA targets. Cell 2005, 120, 15-20. [CrossRef] [PubMed]

66. Small, E.M.; Olson, E.N. Pervasive roles of microRNAs in cardiovascular biology. Nature 2011, 469, 336-342. [CrossRef] [PubMed]

67. Barwari, T.; Joshi, A.; Mayr, M. MicroRNAs in Cardiovascular Disease. J. Am. Coll. Cardiol. 2016, 68, 2577-2584. [CrossRef] [PubMed]

68. Harada, M.; Luo, X.; Murohara, T.; Yang, B.; Dobrev, D.; Nattel, S. MicroRNA regulation and cardiac calcium signaling: Role in cardiac disease and therapeutic potential. Circ. Res. 2014, 114, 689-705. [CrossRef]

69. Zhang, L.; Zhang, Y.; Wang, Y.; Zhao, Y.; Ding, H.; Li, P. Circular RNAs: Functions and Clinical Significance in Cardiovascular Disease. Front. Cell Dev. Biol. 2020, 8, 584051. [CrossRef] [PubMed] 
70. Kura, B.; Parikh, M.; Slezak, J.; Pierce, G.N. The Influence of Diet on MicroRNAs that Impact Cardiovascular Disease. Molecules 2019, 24, 1509. [CrossRef]

71. Cannataro, R.; Perri, M.; Gallelli, L.; Caroleo, M.C.; de Sarro, G.; Cione, E. Ketogenic Diet Acts on Body Remodeling and MicroRNAs Expression Profile. Microrna 2019, 8, 116-126. [CrossRef]

72. Watson, C.J.; Gupta, S.K.; O'Connell, E.; Thum, S.; Glezeva, N.; Fendrich, J.; Gallagher, J.; Ledwidge, M.; Grote-Levi, L.; McDonald, K.; et al. MicroRNA signatures differentiate preserved from reduced ejection fraction heart failure. Eur. J. Heart Fail. 2015, 17, 405-415. [CrossRef]

73. Quan, X.; Ji, Y.; Zhang, C.; Guo, X.; Zhang, Y.; Jia, S.; Ma, W.; Fan, Y.; Wang, C. Circulating MiR-146a May be a Potential Biomarker of Coronary Heart Disease in Patients with Subclinical Hypothyroidism. Cell. Physiol. Biochem. 2018, 45, 226-236. [CrossRef]

74. Oh, J.G.; Watanabe, S.; Lee, A.; Gorski, P.A.; Lee, P.; Jeong, D.; Liang, L.; Liang, Y.; Baccarini, A.; Sahoo, S.; et al. miR-146a Suppresses SUMO1 Expression and Induces Cardiac Dysfunction in Maladaptive Hypertrophy. Circ. Res. 2018, 123, 673-685. [CrossRef]

75. Nakamura, M.; Sadoshima, J. Mechanisms of physiological and pathological cardiac hypertrophy. Nat. Rev. Cardiol. 2018, 15, 387-407. [CrossRef] [PubMed]

76. Houser, S.R.; Molkentin, J.D. Does contractile $\mathrm{Ca}^{2+}$ control calcineurin-NFAT signaling and pathological hypertrophy in cardiac myocytes? Sci. Signal. 2008, 1, pe31. [CrossRef] [PubMed]

77. Da Costa Martins, P.A.; Bourajjaj, M.; Gladka, M.; Kortland, M.; van Oort, R.J.; Pinto, Y.M.; Molkentin, J.D.; de Windt, L.J. Conditional Dicer Gene Deletion in the Postnatal Myocardium Provokes Spontaneous Cardiac Remodeling. Circulation 2008, 118, 1567-1576. [CrossRef]

78. Van Rooij, E.; Sutherland, L.B.; Liu, N.; Williams, A.H.; McAnally, J.; Gerard, R.D.; Richardson, J.A.; Olson, E.N. A signature pattern of stress-responsive microRNAs that can evoke cardiac hypertrophy and heart failure. Proc. Natl. Acad. Sci. USA 2006, 103, 18255-18260. [CrossRef] [PubMed]

79. Kura, B.; Kalocayova, B.; Devaux, Y.; Bartekova, M. Potential Clinical Implications of miR-1 and miR-21 in Heart Disease and Cardioprotection. Int. J. Mol. Sci. 2020, 21, 700. [CrossRef] [PubMed]

80. Ikeda, S.; He, A.; Kong, S.W.; Lu, J.; Bejar, R.; Bodyak, N.; Lee, K.H.; Ma, Q.; Kang, P.M.; Golub, T.R.; et al. MicroRNA-1 negatively regulates expression of the hypertrophy-associated calmodulin and Mef2a genes. Mol. Cell. Biol. 2009, 29, 2193-2204. [CrossRef] [PubMed]

81. Karakikes, I.; Chaanine, A.H.; Kang, S.; Mukete, B.N.; Jeong, D.; Zhang, S.; Hajjar, R.J.; Lebeche, D. Therapeutic cardiac-targeted delivery of miR-1 reverses pressure overload-induced cardiac hypertrophy and attenuates pathological remodeling. J. Am. Heart Assoc. 2013, 2, e000078. [CrossRef]

82. Icli, B.; Dorbala, P.; Feinberg, M.W. An emerging role for the miR-26 family in cardiovascular disease. Trends Cardiovasc. Med. 2014, 6, 241-248. [CrossRef]

83. Gurha, P.; Abreu-Goodger, C.; Wang, T.; Ramirez, M.O.; Drumond, A.L.; van Dongen, S.; Chen, Y.; Bartonicek, N.; Enright, A.J.; Lee, B.; et al. Targeted Deletion of MicroRNA-22 Promotes Stress-Induced Cardiac Dilation and Contractile Dysfunction. Circulation 2012, 125, 2751-2761. [CrossRef]

84. Gurha, P.; Wang, T.; Larimore, A.H.; Sassi, Y.; Abreu-Goodger, C.; Ramirez, M.O.; Reddy, A.K.; Engelhardt, S.; Taffet, G.E.; Wehrens, X.H.; et al. microRNA-22 Promotes Heart Failure through Coordinate Suppression of PPAR/ERR-Nuclear Hormone Receptor Transcription. PLoS ONE 2013, 8, e75882. [CrossRef]

85. Wahlquist, C.; Jeong, D.; Rojas-Muñoz, A.; Kho, C.; Lee, A.; Mitsuyama, S.; van Mil, A.; Park, W.J.; Sluijter, J.P.; Doevendans, P.A.; et al. Inhibition of miR-25 Improves Cardiac Contractility in the Failing Heart. Nature 2014, 508, 531-535. [CrossRef]

86. Jeong, D.; Yoo, J.; Lee, P.; Kepreotis, S.V.; Lee, A.; Wahlquist, C.; Brown, B.D.; Kho, C.; Mercola, M.; Hajjar, R.J. miR-25 Tough Decoy Enhances Cardiac Function in Heart Failure. Mol. Ther. 2018, 26, 718-729. [CrossRef] [PubMed]

87. He, J.; Lu, Y.; Song, X.; Gong, X.; Li, Y. Inhibition of microRNA-146a attenuated heart failure in myocardial infarction rats. Biosci. Rep. 2019, 39, BSR20191732. [CrossRef] [PubMed]

88. Moreira-Costa, L.; Barros, A.S.; Lourenço, A.P.; Leite-Moreira, A.F.; Nogueira-Ferreira, R.; Thongboonkerd, V.; Vitorino, R. Exosome-Derived Mediators as Potential Biomarkers for Cardiovascular Diseases: A Network Approach. Proteomes 2021, $9,8$. [CrossRef]

89. Li, C.; Li, X.; Gao, X.; Zhang, R.; Zhang, Y.; Liang, H.; Xu, C.; Du, W.; Zhang, Y.; Liu, X.; et al. MicroRNA-328 as a regulator of cardiac hypertrophy. Int. J. Cardiol. 2014, 173, 268-276. [CrossRef]

90. Lu, Y.; Zhang, Y.; Wang, N.; Pan, Z.; Gao, X.; Zhang, F.; Zhang, Y.; Shan, H.; Luo, X.; Bai, Y.; et al. MicroRNA-328 contributes to adverse electrical remodeling in atrial fibrillation. Circulation 2010, 122, 2378-2387. [CrossRef] [PubMed]

91. Ucar, A.; Gupta, S.K.; Fiedler, J.; Erikci, E.; Kardasinski, M.; Batkai, S.; Dangwal, S.; Kumarswamy, R.; Bang, C.; Holzmann, A.; et al. The miRNA-212/132 family regulates both cardiac hypertrophy and cardiomyocyte autophagy. Nat. Commun. 2012, 3, 1078. [CrossRef]

92. Lei, Z.; Wahlquist, C.; El Azzouzi, H.; Deddens, J.C.; Kuster, D.; van Mil, A.; Rojas-Munoz, A.; Huibers, M.M.; Mercola, M.; de Weger, R.; et al. miR-132/212 Impairs Cardiomyocytes Contractility in the Failing Heart by Suppressing SERCA2a. Front. Cardiovasc. Med. 2021, 8, 592362. [CrossRef] [PubMed] 
93. Foinquinos, A.; Batkai, S.; Genschel, C.; Viereck, J.; Rump, S.; Gyöngyösi, M.; Traxler, D.; Riesenhuber, M.; Spannbauer, A.; Lukovic, D.; et al. Preclinical development of a miR-132 inhibitor for heart failure treatment. Nat. Commun. 2020, 11, 633. [CrossRef] [PubMed]

94. Talukder, M.A.; Zweier, J.L.; Periasamy, M. Targeting calcium transport in ischaemic heart disease. Cardiovasc. Res. 2009, 84, 345-352. [CrossRef] [PubMed]

95. Weiss, J.B.; Eisenhardt, S.U.; Stark, G.B.; Bode, C.; Moser, M.; Grundmann, S. MicroRNAs in ischemia-reperfusion injury. Am. J. Cardiovasc. Dis. 2012, 2, 237-247.

96. Chistiakov, D.A.; Orekhov, A.N.; Bobryshev, Y.V. Cardiac-specific miRNA in cardiogenesis, heart function, and cardiac pathology (with focus on myocardial infarction). J. Mol. Cell. Cardiol. 2016, 94, 107-121. [CrossRef]

97. Aurora, A.B.; Mahmoud, A.I.; Luo, X.; Johnson, B.A.; van Rooij, E.; Matsuzaki, S.; Humphries, K.M.; Hill, J.A.; Bassel-Duby, R.; Sadek, H.A.; et al. MicroRNA-214 protects the mouse heart from ischemic injury by controlling $\mathrm{Ca}^{2+}$ overload and cell death. J. Clin. Investig. 2012, 122, 1222-1232. [CrossRef]

98. Cha, M.J.; Jang, J.K.; Ham, O.; Song, B.W.; Lee, S.Y.; Lee, C.Y.; Park, J.H.; Lee, J.; Seo, H.H.; Choi, E.; et al. MicroRNA-145 suppresses ROS-induced $\mathrm{Ca}^{2+}$ overload of cardiomyocytes by targeting CaMKIIס. Biochem. Biophys. Res. Commun. 2013, 435, 720-726. [CrossRef]

99. Nattel, S.; Heijman, J.; Zhou, L.; Dobrev, D. Molecular Basis of Atrial Fibrillation Pathophysiology and Therapy: A Translational Perspective. Circ. Res. 2020, 127, 51-72. [CrossRef]

100. Yang, B.; Lin, H.; Xiao, J.; Lu, Y.; Luo, X.; Li, B.; Zhang, Y.; Xu, C.; Bai, Y.; Wang, H.; et al. The muscle-specific microRNA miR-1 regulates cardiac arrhythmogenic potential by targeting GJA1 and KCNJ2. Nat. Med. 2007, 13, 486-491. [CrossRef]

101. Li, Y.D.; Hong, Y.F.; Yusufuaji, Y.; Tang, B.P.; Zhou, X.H.; Xu, G.J.; Li, J.X.; Sun, L.; Zhang, J.H.; Xin, Q.; et al. Altered expression of hyperpolarization-activated cyclic nucleotide-gated channels and microRNA-1 and -133 in patients with age-associated atrial fibrillation. Mol. Med. Rep. 2015, 12, 3243-3248. [CrossRef]

102. Girmatsion, Z.; Biliczki, P.; Bonauer, A.; Wimmer-Greinecker, G.; Scherer, M.; Moritz, A.; Bukowska, A.; Goette, A.; Nattel, S.; Hohnloser, S.H.; et al. Changes in microRNA-1 expression and IK1 up-regulation in human atrial fibrillation. Heart Rhythm 2009, 6, 1802-1809. [CrossRef]

103. Chiang, D.Y.; Kongchan, N.; Beavers, D.L.; Alsina, K.M.; Voigt, N.; Neilson, J.R.; Jakob, H.; Martin, J.F.; Dobrev, D.; Wehrens, X.H.; et al. Loss of microRNA-106b-25 Cluster Promotes Atrial Fibrillation by Enhancing Ryanodine Receptor Type-2 Expression and Calcium Release. Circ. Arrhythm. Electrophysiol. 2014, 7, 1214-1222. [CrossRef]

104. Cañón, S.; Caballero, R.; Herraiz-Martínez, A.; Pérez-Hernández, M.; López, B.; Atienza, F.; Jalife, J.; Hove-Madsen, L.; Delpón, E.; Bernad, A. miR-208b upregulation interferes with calcium handling in HL-1 atrial myocytes: Implications in human chronic atrial fibrillation. J. Mol. Cell. Cardiol. 2016, 99, 162-173. [CrossRef]

105. Van den Berg, N.W.E.; Kawasaki, M.; Berger, W.R.; Neefs, J.; Meulendijks, E.; Tijsen, A.J.; de Groot, J.R. MicroRNAs in Atrial Fibrillation: From Expression Signatures to Functional Implications. Cardiovasc. Drugs Ther. 2017, 31, 345-365.

106. Shen, N.N.; Zhang, C.; Li, Z.; Kong, L.C.; Wang, X.H.; Gu, Z.C.; Wang, J.L. MicroRNA expression signatures of atrial fibrillation: The critical systematic review and bioinformatics analysis. Exp. Biol. Med. 2020, 245, 42-53. [CrossRef] [PubMed]

107. Huang, C.K.; Kafert-Kasting, S.; Thum, T. Preclinical and Clinical Development of Noncoding RNA Therapeutics for Cardiovascular Disease. Circ. Res. 2020, 126, 663-678. [CrossRef] [PubMed]

108. Setten, R.L.; Rossi, J.J.; Han, S.P. The current state and future directions of RNAi-based therapeutics. Nat. Rev. Drug Discov. 2019, 18, 421-446. [CrossRef]

109. Ishikawa, K.; Weber, T.; Hajjar, R.J. Human Cardiac Gene Therapy. Circ. Res. 2018, 123, 601-613. [CrossRef]

110. Chakraborty, C.; Sharma, A.R.; Sharma, G.; Lee, S.S. Therapeutic advances of miRNAs: A preclinical and clinical update. J. Adv. Res. 2020, 28, 127-138. [CrossRef] 